\title{
"Agora abriuse algunha porta e sae toda para fóra": a mímese da memoria na novela galega do século XXI
}

\author{
Diego Rivadulla Costa ${ }^{1}$ \\ Recibido: 14 de xuño de 2019 / Aceptado: 20 de xaneiro de 2020
}

Resumo. Nas últimas dúas décadas, as novelas galegas que tematizan o pasado recente da guerra civil e o franquismo téñense multiplicado e especializado, conformando o corpus da denominada "narrativa da memoria" un subxénero literario propio en Galiza. É a nosa hipótese que un dos principais cambios que amosan os textos publicados a partir do ano 2000 con respecto á produción memorialística anterior é que xa non só constitúen representacións máis ou menos realistas de acontecementos traumáticos relacionados coa resistencia ou a represión franquista, por exemplo, senón que os propios procesos de rememoración -individual e colectiva- daqueles acontecementos xorden como un asunto central na propia diéxese narrativa. No presente traballo ocuparémonos de analizar esta tendencia da representación literaria da memoria ou "mímese da memoria" a través dunha serie de novelas galegas recentes como Expediente Artieda de Luís Rei Núñez, O exiliado e a primavera de Manuel Veiga ou Home sen nome de Suso de Toro.

Palabras chave: memoria cultural; guerra civil; franquismo; narrativa galega; mímese de memoria.

\section{[es] "Agora abriuse algunha porta e sae toda para fóra": la mímesis de memoria en la novela gallega del siglo XXI}

Resumen. En las dos últimas décadas, las novelas gallegas que tematizan el pasado reciente de la guerra civil y el franquismo se han multiplicado y especializado, de forma que el corpus de la denominada "narrativa de la memoria" conforma ya un subgénero propio en Galicia. Es nuestra hipótesis que uno de los principales cambios mostrados por los textos publicados a partir del año 2000 con respecto a la producción memorialística anterior es que ya no solo constituyen representaciones más o menos realistas de acontecimientos traumáticos relacionados con la resistencia o la represión franquista, por ejemplo, sino que los propios procesos de rememoración-individual y colectiva- de aquellos acontecimientos se erigen en asuntos centrales de la propia diégesis narrativa. En este trabajo nos ocuparemos de analizar esta tendencia de la representación literaria de la memoria o "mímesis de memoria" en una serie de novelas gallegas recientes como Expediente Artieda de Luís Rei Núñez, O exiliado e a primavera de Manuel Veiga o Home sen nome de Suso de Toro.

Palabras clave: memoria cultural; guerra civil; franquismo; narrativa gallega; mímesis de memoria.

\section{[en] "Agora abriuse algunha porta e sae toda para fóra": the Mimesis of Mem- ory in Galician Novel of the 21st Century}

\begin{abstract}
In the last two decades, Galician novels that thematize the recent past of the Spanish Civil War and Francoism have multiplied and specialized, so that the corpus of "memory narrative" already forms a literary subgenre of its own in Galicia. It is our hypothesis that one of the main changes shown by the texts published since 2000 with respect to the previous memorialistic novels is that they are not only realistic representations of traumatic events related to resistance or Francoist repression, for example, but rather the processes of individual and collective remembrance of those events are central topics of the narrative digesis itself. This paper proposes an analysis of the literary representation of memory or "mimesis of memory" in a group of recent Galician novels like Expediente Artieda by Luís Rei Núñez, $O$ exiliado e a primavera by Manuel Veiga or Home sen nome by Suso de Toro.
\end{abstract}

Keywords: Cultural Memory; Spanish Civil War; Francoism; Galician Narrative; Mimesis of Memory.

Sumario. 1. Introdución. 2. A memoria cultural na literatura ou mímese de memoria. 3. A memoria cultural da guerra civil e o franquismo en Galiza. 4. A novela galega da memoria no século XXI. 5. Análise da mímese de memoria nos textos. 5.1. Expediente Artieda. 5.2. Como levar un morto. 5.3. O tempo en ningunha parte. 5.4. O exiliado e a primavera.

1 Universidade da Coruña. Departamento de Letras, Grupo de Investigación Lingüística e Literaria Galega (ILLA). Correo-e: diego.rivadulla@udc.gal; https://orcid.org/0000-0002-0163-8140. 
5.5. Home sen nome. 5.6. Non hai noite tan longa. 5.7. Seique. 6. Remate. 7. Referencias bibliográficas.

Como citar: Rivadulla Costa, D. (2020): “"Agora abriuse algunha porta e sae toda para fóra»: a mímese da memoria na novela galega do século XXI", en Madrygal. Revista de Estudios Gallegos 23 Núm. Especial, pp. 293-306.

\section{Introdución}

O obxectivo deste traballo é achegármonos ao corpus da narrativa galega actual que trata do pasado traumático da guerra civil e a ditadura franquista para analizar en que medida funciona como un medio a través do que observar a produción de memoria cultural no contexto do boom memorialista e interese polo pasado que ten lugar durante as dúas últimas décadas en Galiza. O feito de a memoria desenvolver un importante papel tanto en termos temáticos coma formais nalgunhas das obras que compoñen este corpus permite aventurar a hipótese de que a chamada "mímese de memoria" constitúe unha tendencia común na novela producida a partir do 2000. Para o demostrar, comezaremos, en primeiro lugar, por revisar a importancia da literatura nos estudos de memoria e explicar o concepto teórico da "mímese de memoria" para, a seguir, ocupármonos do desenvolvemento da memoria cultural da guerra civil, a resistencia e a represión franquistas en Galiza; en terceiro lugar repasaremos brevemente as principais características da narrativa galega da memoria publicada no século XXI, que se ten especializado e multiplicado, constituíndo un subxénero literario propio; finalmente, exemplificaremos a práctica da representación literaria da memoria achegándonos ao caso concreto dunha serie de obras recentes seleccionadas para tal fin.

\section{A memoria na literatura ou mímese de memoria}

A relación entre literatura e memoria tense convertido en obxecto de atención recorrente especialmente desde os anos 80 do século pasado, durante o que Astrid Erll (2008: 8) ten definido como unha nova época dos estudos de memoria, o momento en que o tópico da memoria colectiva, con base nos textos fundacionais do sociólogo francés Maurice Halbwachs, comeza a destacar na investigación académica. Neste contexto xorde a noción de "memoria cultural", que se converterá a partir dos traballos de Jan e Aleida Assmann nun dos conceptos máis empregados para describir as complexas formas en que as sociedades recordan o seu pasado a través dunha ampla variedade de medios e prácticas. A noción foi adoptada no marco dos estudos culturais, onde se converteu nun concepto equivalente ao de memoria colectiva -sendo empregados ambos como sinónimos- e foi arredor dela que se constituíu nas dúas últimas décadas o emerxente eido dos denominados Cultural Memory Studies. Trátase dun campo de investigación interdisciplinar que desde os últimos anos do século XX se vén ocupando especialmente do estudo das dinámicas da cultura da memoria ${ }^{2}$ en diversos ámbitos, ben como da relación entre pasado, identidade, cultura e medios de comunicación (Erll e Nünning 2016: 261) . $^{3}$.

Entendemos aquí a memoria cultural, de acordo con Erll, como "the interplay of present and past in socio-cultural contexts" (Erll 2008: 2). Unha definición ampla que acentúa a conexión do recordo colectivo cos contextos socioculturais e parte dun uso metafórico do termo "memoria", de modo que o proceso cognitivo de recordar que ten lugar nos cerebros individuais é transferido metaforicamente ao nivel da cultura. Para precisarmos máis un pouco, vexamos como a especialista Sara Santamaría define a reelaboración que do concepto de "memoria cultural" foi realizada nos estudos culturais:

La memoria cultural permite dar cuenta del vínculo activo y constante entre el pasado y el presente. Este concepto subraya el carácter mediado y textualizado de las memorias compartidas y presta atención a los actos de comunicación. La memoria cultural constituye así una memoria mediada, vicaria, que pone énfasis en los procesos culturales y no en la experiencia vivida directamente de forma "no mediada". La memoria cultural es un proceso performativo y

2 A “cultura da memoria" é un concepto de uso habitual nos estudos de memoria. Enténdese aquí, seguindo a Santamaría Colmenero (2013: 30), como o modo heteroxéneo de situarse no tempo e no espazo e de relacionarse co pasado, o presente e o futuro, e que se ten manifestado como un revulsivo fronte á apreciación dunha ruptura inevitábel con respecto ao pasado, como consecuencia da constante aceleración do tempo nun paradóxico presente infinito.

3 Cómpre mencionarmos o volume Cultural Memory Studies. An International and Interdisciplinary Handbook (Erll e Nünning 2008) como unha primeira achega loábel á teorización do campo de estudo, ben como o compendio coordinado por varias investigadoras do Centro de Estudos Comparatistas da Universidade de Lisboa, Estudos de Memória. Teoria e análise cultural (Mota Alves, Afonso Soares e Vasconcelos Rodrigues 2016). 
dinámico llevado a cabo tanto por individuos como por grupos a través de prácticas memoriales. (Santamaría Colmenero 2018: 284)

O carácter mediático, dinámico e perfomativo da memoria cultural convida á investigación sobre os medios que, como a literatura, a constrúen, ben como sobre o papel desenvolvido por estes en culturas da memoria específicas e en relación co presente. Non debe sorprender, por tanto, o enorme interese suscitado polo estudo da memoria entre os estudosos da literatura. Tanto é así que, a respecto da teorización da relación entre literatura e memoria a partir do concepto de "memoria cultural" formulado polos estudos culturais a comezos do século XXI, Astrid Erll e Ansgar Nünning (2016: 261-262) formulan a hipótese de os "estudos sobre o literário enquanto memória cultural" constituíren un campo de investigación independente cunha perspectiva dupla: o estudo do papel da literatura en culturas da memoria, por un lado, e a análise do papel da memoria cultural na literatura, polo outro.

Consonte o anterior, coa intención de estudar o papel específico da literatura no proceso de construción da memoria cultural, nun traballo do ano 2006 Astrid Erll e Ann Rigney (2006: 112-113) apuntaban tres direccións principais que sintetizan esta relación e que nos parece interesante referir aquí.

En primeiro lugar, a literatura pode ser concibida como obxecto de recordo, pois o feito de recordarmos textos escritos en épocas anteriores constitúe unha parte integral da memoria cultural, de modo que a literatura se atribúe, en termos metafóricos, unha memoria propia, cuxa investigación se materializa, por exemplo, nos estudos dos procesos de formación do canon e de construción das historias das literaturas, aspectos para os que Erll e Nünning (2016: 248) teñen proposto o concepto de "memoria da literatura", metáfora que serve tamén para se referir á análise da intertextualidade. A revisión de como as sociedades discuten cales textos deben ser considerados fundacionais e, por tanto, ser conmemorados e canonizados desde os estudos literarios é, como se dixo, unha das principais direccións da investigación neste ámbito.

En segundo lugar, a literatura pode funcionar como medio de recordo, quere dicir, unha sociedade pode lembrar o seu pasado a través das obras de ficción. O rol da literatura como medio de memoria refírese á capacidade dos textos literarios para produciren memorias colectivas, isto é, ás funcións que os textos literarios desenvolven na formación e transformación da memoria cultural dun determinado contexto (Erll e Nünning 2016: 248). A súa investigación pregúntase, por exemplo, polos modos en que a escritura de novelas históricas, dramas históricos ou autobiografías dá forma aos nosos puntos de vista sobre o pasado. Traballos como os de Elina Liikanen (2015) sobre a narrativa española recente que trata da guerra civil e o franquismo teñen demostrado que estas obras poden chegar a se converter, se o contexto é apropiado, en potentes medios de memoria que realizan as funcións de almacenamento e circulación de versións dese pasado que están a ficcionalizar.

Finalmente -e isto é o que aquí máis nos interesa-, a literatura pode funcionar como medio para observar a propia produción de memoria cultural. Tal e como apuntan Erll e Rigney, a literatura non só participa na construción da memoria colectiva senón que as obras literarias, ao presentaren ficcionalmente os actos de recordo, fan observábel a memoria, contribuíndo ao coñecemento cultural sobre como funcionan as dinámicas do recordar nos individuos e nos grupos sociais. Trátase do ámbito de investigación da "memoria na literatura" ou "mímese de memoria", isto é, dos estudos que se ocupan das formas de escenificación estética ou representación literaria da memoria (Erll e Nünning 2016: 257).

Foi Birgit Neumann quen acuñou a expresión "mímese da memoria" para aludir a aquelas narrativas que presentan ficcionalmente os actos de recordo, facéndoo observábel e reflexionando así sobre a epistemoloxía, a ética e o funcionamento da memoria colectiva. En palabras de Neumann (2008: 334), "This term refers to the ensemble of narrative for$\mathrm{ms}$ and aesthetic techniques through which literary texts stage and reflect the workings of memory". O concepto da "mímese de memoria" parte da premisa de que a literatura se refire á realidade cultural extratextual, tornándoa visíbel por medio da ficción, e de que, con este obxectivo, as obras literarias estabelecen unha relación dialóxica cos discursos extraliterarios contemporáneos de memoria, sendo deste modo como conseguen ilustrar funcións, procesos e problemas da memoria no medio ficcional (Erll e Nünning 2016: 248-257), tal e como veremos que sucede na novela galega actual sobre o pasado recente. De acordo con Neumann, quen ten estudado en profundidade 
as narrativas de ficción nas que os procesos de rememoración son un tópico central:

Many contemporary novels problematize the processes of remembering on a meta-level and foreground the ways in which memories are constructed. Such fictions of meta-memory, as one could aptly call them, combine personally engaged memories with critically reflective perspectives on the functioning of memory, thus rendering the question of how we remember the central content of remembering. (Neumann 2008: 337)

En síntese, de acordo co anterior, este traballo parte da premisa de que a propia memoria colectiva, quere dicir, as súas prácticas, loitas e realizacións, son observábeis a través dos textos literarios, de modo que a literatura está en condicións de achegar reflexións sobre as relacións entre pasado e presente en contextos socioculturais específicos. É a nosa hipótese que a novela galega que rememora a guerra civil, a violencia vinculada á represión franquista ou a resistencia antifranquista, publicada nas últimas dúas décadas reflicte, a través da mímese de memoria, o funcionamento do recordo individual e colectivo, ao tempo que participa da reflexión sobre a lembranza, interpretación e xestión do pasado no contexto de recuperación da memoria histórica en Galiza.

\section{A memoria cultural da guerra civil e o franquismo en Galiza}

Nos traballos sobre a memoria histórica en España é habitual atoparmos a alusión a un "pacto de silencio" adoptado na Transición como explicación da amnesia pública, social e política, que durante décadas rodeou o pasado conflitivo de 1936 e ás vítimas da represión franquista. Se ben é certo que o acordo transicional xestado tras a morte de Franco constitúe un momento determinante para entender o posterior proceso de recuperación da memoria histórica en Galiza e no conxunto do Estado español, o xerme dese silencio haberá que o procurar moitos anos atrás de 1975:

O silencio respecto deste tema non o inicia a Transición, nin tan sequera o crea o réxime franquista, aínda que evidentemente o desenvolve e perfecciona. [...] O proceso do silencio iníciase na vontade manifesta de facer desaparecer, de borrar, de limpar todo rastro das persoas que foron sacadas das súas casas de noite, ou das que sacaron, tamén de noite, da cadea para seren masacradas por sectores paramilitares e fascistas... O silencio iníciase coa vontade de converter en "desaparecidas" [...] todas as persoas que participaran, sentiran e interiorizaran a necesidade de vivir nunha sociedade máis xusta e libre. (Pereira, Fernández e Grandío 2011: 9)

É importante comezarmos por lembrar que o franquismo se instaurou en Galiza tras o inmediato triunfo do sanguento golpe de estado de xullo do 1936. Como ten explicado Carlos Velasco (2006: 13), aquí non houbo fronte de guerra en sentido convencional mais si unha "auténtica guerra de exterminio contra civís desarmados; contra todo aquilo que representase, simbolizase ou evocase o réxime democrático republicano nacido en abril de 1931 e, moi especialmente, a vitoria electoral da Frente Popular en febreiro de 1936". Tras o triunfo da sublevación militar, a instauración do novo poder político encabezado por Franco e, como ten analizado Antonio Míguez Macho (2009: 16), a institucionalización da represión como elemento central do funcionamento do novo réxime, o franquismo encargouse de construír unha memoria dos vencedores na que guerra civil era unha referencia mítica, así como de a converter na única memoria oficial e pública durante os anos da ditadura. O relato hexemónico que estabelecía que a República fora a causa da guerra e os golpistas os salvadores da unidade da patria mantívose até hai ben poucos anos e segue aínda presente en parte da sociedade, que non conseguiu reivindicar o réxime republicano como un pasado político colectivo antecedente da democracia actual (Fernández Prieto e Artiaga 2013), sendo unha das poucas experiencias totalmente democráticas que tivo o Estado español antes de 1975.

Durante a ditadura, a memoria pública dos sucesos que comezaran no 36, construída e xestionada polos verdugos, na que eran vítimas todos os "caídos por Dios y por España", conviviu coa memoria patolóxica, á que non se lle permite expresar publicamente a dor, das vítimas da violencia xenocida, que se materializa, segundo Míguez Macho (2009: 137-143): por unha parte, nunha memoria silenciosa que non renuncia ao recordo privado dos feitos, construída sobre o discurso negacionista e de carácter sentimental e apolítico; por outra, no esquecemento consciente, é dicir, na vontade de desterrar incluso do ámbito privado toda mención do sucedido; e, finalmente, nunha memoria militante, politicamente consciente e reivindicativa, existente en parte dos superviventes e as familias das vítimas, actitude que se convertería progresivamente en militancia activa antifranquista, polo camiño da loita armada 
contra a ditadura que representou a guerrilla ou polo da militancia na clandestinidade, para alén dos superviventes no exilio.

Só no ámbito familiar e íntimo se transmitiron durante anos, pois, de maneira máis ou menos traumática, as memorias das vítimas, na maioría dos casos unha memoria despolitiza$\mathrm{da}$, entre outros motivos pola consciencia de que a significación social podía levar á morte ou á prisión e polo pensamento estigmatizante de que a política fora un mal que provocara a traxedia persoal e familiar, segundo teñen analizado Domínguez e Somoza (2013: 75) para quen o recordo da represión no ámbito familiar se tería alzado durante anos sobre o esquecemento da política, dando lugar ao que se podería denominar un "antifranquismo sociolóxico”. Lourenzo Fernández Prieto (2011: 105-106), coincide en sinalar o empeño en pasar páxina sobre un episodio doloroso e inxusto do pasado por parte das persoas perseguidas ou expedientadas nos primeiros anos da ditadura. No entanto, o esquecemento público convive cunha potente memoria privada sobre a represión que persiste no tempo e incluso no exilio. De feito, para o catedrático de historia contemporánea, a vontade social de recordar e coñecer que se abre paso nas últimas décadas é un potente motor alimentado polo recordo privado que pasa de vítimas a fillos e, sobre todo, a netos.

Coa morte de Franco en 1975 e a chegada da denominada Transición da ditadura á democracia no Estado español abriuse un contexto de esperanza en que se daba a posibilidade de impulsar unha efectiva reconstrución da nosa memoria histórica democrática, mais as expectativas ben logo se verían frustradas (Velasco Souto 2012: 76). O suposto éxito da Transición, vista durante anos como modelo internacional de ruptura co pasado traumático e de proceso pacífico grazas á moderación e ás cesións mutuas, tende a atribuírse a un "pacto" entre os reformistas do réxime e os moderados da oposición antifranquista, que a bibliografía ten denominado indistintamente "pacto de silencio" ou "pacto de olvido", en referencia á decisión colectiva de "pasar páxina" do pasado violento na que o silencio foi unha das consecuencias máis importantes (Aguilar e Payne 2018: 1518). O certo é que, a pesar da grande curiosidade que xurdiu polo pasado recente tras a morte do ditador e da produción cultural que comezou a emerxer -as primeiras novelas galegas da memoria, por exemplo-, no ámbito político, e en boa medida tamén no social, triunfou a idea de arrombar ese pasado (Ibid.: 139). Tal como explica Fernández Prieto (2011: 99), a reconciliación entendeuse como esquecemento da guerra civil, como "amnistía" e decisión de "botar ao esquecemento" aspectos traumáticos da guerra civil e a represión e na que non hai, por suposto, políticas de reparación:

No hubo un pacto de silencio de los políticos en la Transición sino un pacto del que participó la inmensa mayoría de la sociedad. Un acuerdo general de mirar hacia adelante y olvidar lo que el franquismo había hecho recordar hasta el último minuto de la vida del Dictador: la guerra como victoria de unos y derrota de otros. Esa, llamémosla, vocación social, estuvo por supuesto aderezada y representada en aquella ruptura pactada de la que la Ley de Amnistía es un ejemplo perfecto. (Fernández Prieto 2009: 131)

O consenso social materializouse en que a memoria da guerra e da represión franquista continuou ocultada no ámbito privado nas dúas décadas posteriores á morte de Franco, nas que o debate sobre o pasado traumático en Galiza, como no conxunto de España, foi moi escaso. De acordo coa periodización proposta por Fernández Prieto (2009: 139) para a recuperación da memoria da guerra civil e do franquismo até hoxe, entre 1975 e 1996, como ao longo de toda a ditadura, esta prevalece e renóvase dentro das familias:

Se trata de una memoria ocultada -lo que no quiere decir olvidada-. Es una memoria fragmentaria con ciertas repercusiones en la esfera pública, por ejemplo en libros y películas que tratan el tema. [...] Pero apenas hay actuaciones que puedan destacarse como políticas públicas de memoria.

4 A estes motivos do esquecemento da política, entendida como actividade real ou como protagonista da memoria transmitida dos vencidos, sumaríanse o cuestionamento da utilidade de transmitir unha memoria política determinada nun contexto de ausencia de liberdades en que a práctica política é imposíbel, así coma o feito de que a transmisión da memoria recaía maioritariamente nas mulleres pouco alfabetizadas, menos politizadas e con outras estratexias de resistencia, que priorizan nos seus relatos o coñecemento humano e o padecemento das vítimas (Domínguez e Somoza 2013: 75-76). 
Non será até 1996 cando a memoria da guerra e do franquismo pase da memoria das familias ao debate social para, desde o 2000, pasar á política e ao debate político, acompañando a ese crecente debate social e instalándose no poder executivo a partir do ano 2004 e no xudicial desde o 2008 (Ibid.: 139). As memorias da represión que sucedeu ao golpe de Estado de 1936, que durante décadas permaneceran ocultadas e que se conservaran e renovaran oralmente -de maneira case clandestina- no ámbito familiar e privado, onde se transmitiran aos descendentes das vítimas, comezan a ser apreciadas, no contexto dunha cultura da memoria contemporánea a nivel global, como unha fonte de coñecemento útil para a sociedade por parte dunha xeración máis nova -maioritariamente a dos chamados "netos da guerra", que non asinara o acordo social da Transicióna que lle interesa o que pasou, recuperar a memoria e incorporala ao coñecemento histórico, falseado por anos de memoria oficial da ditadura (Domínguez e Somoza 2013: 77). Houbo que agardar, pois, até o cambio de milenio para que en Galiza, paralelamente ao que sucede no resto do Estado, se producise unha ruptura do silencio, onde a denominada "recuperación da memoria histórica" se viu impulsada polo movemento asociativo e social que xorde coas primeiras exhumacións de fosas comúns e coa creación da ARMH ou da plataforma Iniciativa Galega pola Memoria, entre outras moitas, que reclaman xustiza, verdade e reparación para as vítimas do franquismo.

A creación de monumentos como o do Campo da Rata coruñés - dedicado aos republicanos fusilados naquel lugar desde o ano 36- ou a celebración dos primeiros Congresos da Memoria, que impulsaran definitivamente a investigación sobre a represión franquista, son as mostras tanxíbeis dunha nova relación coa memoria do pasado traumático galego, que se institucionaliza entre os anos 2005 e 2009, durante o goberno bipartito de esquerdas na Xunta de Galicia -formado polo PSdG e o BNG-, que, como apunta Lourenzo Fernández Prieto (2009: 141), leva a cabo por primeira vez unha auténtica política de memoria no país ${ }^{5}$. Embora a situación mudase unha vez que a dereita recuperou o poder na Xunta, as institucións locais e provinciais gobernadas pola esquerda política continuaron nos últimos anos a impulsar importantes políticas da memoria: a modo de exemplo, a chegada ás alcaldías de tres das principais cidades galegas (A Coruña, Santiago e Ferrol) dos chamados "gobernos do cambio" supuxo, como prometían os seus respectivos programas electorais ${ }^{6}$, que se retomase de maneira efectiva a aplicación no ámbito local da Lei de Memoria Histórica do ano 2007, especialmente no que se refire aos cambios no rueiro e á retirada de símbolos franquistas. Aliás, o movemento social de recuperación da memoria segue tamén plenamente vixente en Galiza, como mostra a loita pola devolución do Pazo de Meirás como ben público, que ao longo destes anos ten recibido unha atención constante por parte dos medios de comunicación.

Con todo, cómpre sinalarmos que a cuestión da memoria en Galiza, como no conxunto do Estado español, lonxe de ser un asunto de consenso, nos últimos vinte anos estivo rodeada de polémicas e tensións, constituíndo unha loita pola interpretación e xestión do pasado que se escenifica no espazo público e perdura na actualidade. Dado que a guerra civil era para a

5 Entre as numerosas iniciativas que gozaron dun apoio institucional durante o período 2005-2009, que ben podería ser definido como a "lexislatura da memoria", cómpre destacarmos, seguindo a Velasco (2011: 82-83), a financiación de todo tipo de actividades relacionadas coa memoria histórica a través de varias convocatorias públicas de axudas; a organización dun congreso específico que dera continuidade aos celebrados nos anos previos; a celebración de eventos de forte impacto mediático e contido emotivo coa participación dos colectivos de represaliados e os seus familiares, como os desenvolvidos na Illa de San Simón (antiga prisión política franquista convertida en centro de referencia para a recuperación da memoria histórica de Galiza); a promoción de exposicións itinerantes como as intituladas "Memorial de Liberdade", sobre a represión franquista e a resistencia democrática en Galiza, e "A Illa da memoria. A represión no cárcere da Illa de San Simón (1936-1943)", ben como a experiencia do "Barco da Memoria", que percorreu os portos galegos tamén cunha mostra sobre a represión contra "Os Mártires do Mar"; a constitución do Consello da Memoria, como organismo de supervisión e coordinación de actividades relacionadas coa memoria histórica; e, finalmente, a posta en marcha do proxecto de investigación interuniversitario "As vítimas, os nomes e as voces", que tiña como obxectivo central o de recompilar información para creación dun futuro centro de memoria sobre a guerra civil e o franquismo.

6 Referímonos ás plataformas cidadás denominadas Marea Atlántica, Compostela Aberta e Ferrol en Común, encabezadas por Xulio Ferreiro, Martiño Noriega e Jorge Suárez, respectivamente, que se fixeron co poder nas eleccións locais do mes de maio de 2015. 
democracia española un pasado pretérito e incómodo sobre o que prevalecía o esquecemento acordado na Transición, as reivindicacións do movemento memorialista foron desde o seu comezo percibidas por certos sectores sociais como unha innecesaria resurrección de vellos fantasmas, unha incómoda revisión dun tema que fora sempre considerado espiñoso (Gómez López-Quiñones 2006: 20-21). Esta "loita" ou "conflito de memorias", para a que se acuñaran expresións metafóricas como "espertar os fantasmas", "desenterrar os mortos", "remover o pasado" ou "reabrir vellas feridas", máis que entre revanchistas e asépticos, ou neutrais e activistas, prodúcese "entre dos versiones divergentes de carácter político sobre cómo debe ser tratado el recuerdo y los restos físicos de aquel enfrentamiento" (Gómez López-Quiñones 2006: 20-22). Pedro Ruiz (2007: 17), un dos historiadores que mellor ten analizado as dúas posturas encontradas, sinala que os discursos a favor da recuperación da memoria das vítimas individuais e colectivas do franquismo se caracterizan por seren moi críticos coa Transición -á que acusan de ter propiciado o esquecemento- e por reivindicaren a memoria democrática da República e dos que loitaron por ela, o que vai acompañado dunha exixencia de reparación moral, política e xurídica das vítimas. Pola contra, os discursos a favor de deixar as cousas como están en relación co pasado recente son discursos inmobilistas que consideran calquera reivindicación da República ou reparación efectiva das vítimas do franquismo como unha perigosa ruptura do consenso estabelecido durante a Transición. Aínda que non hai espazo para afondarmos máis, podemos afirmar que, aínda a día de hoxe, o conflito de memorias na Galiza contemporánea vai máis alá do debate político e dunha discusión entre historiadores, involucrando a unha boa parte da sociedade, que participa nun diálogo público sobre a interpretación e xestión do pasado conflitivo e traumático colectivo.

\section{A novela galega da memoria no século XXI}

A literatura galega, como ten analizado en múltiples ocasións Dolores Vilavedra $(2011)^{7}$, comeza a tratar o tema da guerra civil e do franquismo de maneira serodia, non sendo até a segunda metade dos 80 e ao longo dos anos
90 cando a produción de novelas sobre o asunto acada un considerábel pulo da man dunha xeración de autores nacidos despois de 1930 entre os que destacan Carlos Casares ou Xosé Fernández Ferreiro. Porén, é desde finais dos anos 90 e especialmente a partir do 2000 cando se produce unha verdadeira eclosión de novelas galegas que tematizan o pasado da guerra e da ditadura, un fenómeno que Vilavedra (2011: 72) explica desde o punto de vista xeracional, pola aparición dun novo grupo de autores nados nos anos 50, entre os que destacan Manuel Rivas ou Suso de Toro, e decididos a tomar a palabra porque "no se sentían comprometidos por ningún pacto de silencio, por la simple razón de que no habían sido ellos los que lo firmaron". Asistiremos, deste modo, a unha evolución cara a fórmulas abertamente ficcionais, en detrimento da crónica histórica, recreando situacións das que as novas xeracións están cada vez máis afastadas cronoloxicamente e, ao tempo, máis próximas desde o punto de vista emocional, debido á crecente receptividade social do tema (Ibid.: 71).

Con efecto, a ruptura do pacto de silencio sobre o pasado recente, e o consecuente boom de memoria que ten lugar na entrada do século XXI en Galiza como no resto do Estado español, provoca un contexto de "recuperación da memoria histórica" do que a literatura participa e que explica, en boa medida, a proliferación nestes anos do que poderiamos denominar unha "nova novela galega da memoria" que vai amosar, a respecto da anterior, unha considerábel evolución nos modos de representación e fórmulas empregadas no tratamento do pasado recente. Neste sentido, concordamos con Hans Lauge Hansen en que o contexto memorialista está a repercutir na elaboración da narrativa que participa dese fenómeno desde os primeiros anos do século XXI, tanto desde o punto de vista temático como formal, quere dicir, a participación da literatura no diálogo entre discursos sociais que se estabelece na esfera pública sobre a interpretación da historia recente "influye en la misma forma de contar del discurso novelístico y en la manera de plasmar los universos ficticios" (Hansen 2012: 83).

A novela galega sobre a guerra civil e a ditadura franquista producida a partir do 2000 incorpora importantes novidades formais entre 
as que destacan, do noso punto de vista, o uso do molde narrativo da nova novela histórica, que provoca a división da trama en dous planos ou niveis temporais, ou tamén a aposta por un multiperspectivismo que serve para outorgar voz ás vítimas do franquismo, mais tamén por vez primeira aos verdugos, como exemplifican os casos d'O lapis do carpinteiro (1998) de Rivas ou de Home sen nome (2006) de Suso de Toro. Aliás, a hibridación xenérica, que ten sido sinalada pola crítica como un trazo recorrente -e ás veces tamén intrínseco- da nova novela da memoria en España ${ }^{8}$, comeza a se facer visíbel na narrativa galega do novo milenio a través da incorporación de estratexias metaliterarias propias da metaficción historiográfica, como sucede en obras como O tempo en ningunha parte (2003) de Xosé Manuel Martínez Oca, de tramas de investigación próximas ao xénero policial -Non hai noite tan longa (2011) de Agustín Fernández Paz-, da inclusión de trazos do thriller-Expediente Artieda (2000) de Luís Rei Núñez-, de elementos da denominada novela de non ficción ou nonfiction novel-Polos fillos dos fillos (2003) de Xosé Manuel Sarille ou A lingua secreta (2002) de Xesús González Gómez- ou das denominadas formas do "eu"-Como levar un morto (2001) de Xesús Rábade Paredes-e incluso do fantástico -Non volvas (2000) de Suso de Toro-, até chegar á ambigüidade xenérica total-Seique (2015) de Susana Sánchez Aríns-, que denota a evolución da literatura galega da memoria tras unha longa traxectoria de experimentación e innovacións.

No que respecta ao nivel do contido, en termos xerais esta narrativa segue a recuperar e evocar a memoria das vítimas republicanas, aquela que até o momento seguía en boa parte silenciada e relegada ao ámbito privado, mais a especificidade do caso galego a respecto da produción memorialística doutros ámbitos literarios peninsulares hai que a procurar nas propias circunstancias históricas sinaladas con anterioridade. Cómpre recordarmos, pois, como afirma Lourenzo Fernández Prieto (2007: 16), que "a Guerra Civil na Galiza resúmese en 15 días de guerra, 15 anos de escapados e 20 anos de posguerra" para aclararmos que desde o punto de vista temático se trata, máis que de novelas da guerra civil, de novelas da posguerra (Vilavedra 2011: 74), ou de novelas da memoria do franquismo. Isto é, dada a inexistencia de fronte bélica en Galiza durante o período da guerra española ${ }^{9}$, o contido destas obras -isto resulta fundamental- vai xirar arredor de tres grandes núcleos temáticos que se corresponden a grandes trazos coas consecuencias do triunfo do golpe de Estado de xullo do 36 e a inmediata implantación do poder franquista neste territorio: a represión, a resistencia e, en menor medida, o exilio ${ }^{10}$.

A través deses tres grandes ámbitos temáticos os autores recuperan, á súa vez, memorias máis concretas, isto é, a través de elaborados procesos de ficcionalización de historias de orixe real, herdadas e/ou documentadas a través de numerosas fontes tanto orais como escritas, dan a coñecer a multiplicidade de dramas particulares provocados polo franquismo ao longo de corenta anos: fusilamentos, paseos, consellos de guerra, prisión, campos de concentración, persecucións, maltrato, tortura, ben como as súas consecuencias posteriores. Con todo, o tema máis prolífico podemos dicir que é o da resistencia antifranquista $-O s$ últimos fuxidos (2004) de Xosé Fernández Ferreiro, Intramundi (2002) e $A$ vitoria do perdedor (2013) de Carlos Reigosa, Agora xa foi (2000) de Vicente Araguas, Iria (2012) de Anxo Angueira, Escapados nos eidos das Foucellas (2007) de Andrés Mariño son só algúns exemplos-, a partir sobre todo das historias concretas de fuxidos nos montes galegos e da loita armada levada a cabo pola guerrilla conformada arredor deles.

A novidade fundamental desde o punto de vista temático radica, non obstante, no tratamento da memoria como tema na diéxese

8 A este respecto, véxanse os traballos compilados no primeiro volume de La memoria novelada (Hansen e Cruz Suárez 2012), subtitulado Hibridación de géneros y metaficción en la novela española sobre la guerra civil y el franquismo (2000-2010).

9 Como xa sinalou Vilavedra (2011: 74), son escasísimos os episodios bélicos nas novelas galegas da memoria e os poucos que se rexistran están localizados fóra de Galiza, como pode ser o caso da batalla do Ebro en Entre fronteiras (2004) de Xavier Alcalá.

10 Se ben non hai tantas novelas que representen a experiencia do exilio provocado pola sublevación militar do 36 e a guerra civil en xeral, contamos con algúns exemplos dabondo representativos como Sol de Inverno (2009) de Rosa Aneiros, O encargo do señor Castelao (2016) de Luís Rei Núñez ou incluso O exiliado e a primavera (2004) de Manuel Veiga. 
ficcional. Mentres que a novela sobre a guerra civil e o franquismo das décadas anteriores non se detiña en falar dos procesos de memoria, a narrativa actual vaise ocupar de ficcionalizar as dinámicas individuais e colectivas do recordo, incorporando como trazo definitorio a representación literaria ou mímese da memoria. Trátase de máis unha mostra de como o contexto externo de debate público sobre o pasado e sobre a recuperación da memoria inflúe na creación literaria, e de como ambos se retroalimentan ${ }^{11}$. A negociación sobre a memoria cultural, a ruptura do silencio e/ou da amnesia sobre o pasado, a recuperación de memorias esquecidas, a procura de xustiza e reparación para as vítimas ou a reflexión sobre a transmisión do recordo e a súa influencia no presente son temas que ocupan unha posición central en obras do novo milenio que pretenden, seguindo a Hansen (2012: 89), describir, discutir e reflexionar sobre os procesos sociais que contribúen á produción dunha memoria cultural nunha determinada sociedade. A novela trasládase, así, do tema do franquismo para o da memoria do franquismo, da ficcionalización do pasado para a problematización dese pasado, da evocación para a reflexión e da mímese da realidade fáctica para a "mímese de memoria".

O propio John Thompson, no seu estudo sobre as novelas galegas da memoria, se refire a esta cuestión ao distinguir, fronte á novela de tipo realista, aqueloutras narracións "que tentan dalgún xeito facer máis tanxíbeis as dinámicas labirínticas ao redor da transmisión e recepción da memoria histórica" e que, por tanto, "van acompañadas dun compoñente meta-memorialístico", un compoñente que, para o especialista, é medular da nova novela histórica, o subxénero principal empregado polos autores de $2^{\mathrm{a}}$ e $3^{\mathrm{a}}$ xeración, pois, segundo el mesmo indica, "esta preocupación do autor polo acto de transmisión de memoria, mesmo máis que pola memoria propia, débese a que os autores se senten cada vez máis afastados dos feitos" (Thompson 2009: 60). Contido e forma van, por tanto, da man nesta nova novela da memoria cuxa trama central se basea, frecuentemente, na recuperación ou reconstrución dun pasado que está a condicionar a vida dos protagonistas contemporáneos, convertendo a reflexión nun eixo central na dirección do que Astrid Erll denominou "reflexive mode" referíndose a aquelas novelas que funcionan como medio de reflexión crítica sobre os procesos de rememoración que ao tempo constrúe e observa a memoria, os seus problemas ou as súas contraditorias reflexións (Erll 2011: 159).

\section{Análise da mímese de memoria nos textos}

Unha vez expostas as principais direccións da narrativa memorialística actual, aproximarémonos nas liñas que seguen a unha serie de novelas galegas publicadas no século XXI seleccionadas ad hoc para abordar a representación literaria da memoria individual e cultural da guerra civil e a ditadura franquista que realizan. Achegarémonos, por tanto, a un corpus heteroxéneo de títulos recentes, entre os que se atopan algúns dos máis coñecidos e representativos do xénero, desde a perspectiva da mímese de memoria coa intención de vermos de que xeito e en que medida as autoras e autores galegos a asumen e incorporan.

\subsection{Expediente Artieda}

Con Expediente Artieda, Luís Rei Núñez fíxose co Premio Xerais de Novela no ano 2000. A obra trata sobre a resistencia antifranquista, mais lonxe de ser unha historia de maquis que tematiza a loita armada, coloca o foco na militancia política clandestina e as súas circunstancias na Coruña de finais dos anos cincuenta e, especialmente, nas vidas e destinos individuais dos que compoñen ese núcleo da resistencia na cidade. A trama principal está protagonizada por un militante comunista que chega á cidade co obxectivo de investigar e vingar a traizón que causou a morte de catro camaradas nunha acción guerrilleira. A partir dese inicio é que se despregan a través dunha estrutura fragmentaria innumerábeis tramas secundarias cuxos personaxes se relacionan ligando todas as historias coa principal e facendo que todas conflúan nos capítulos finais da novela, formando un mosaico da vida na resistencia, cuxa homenaxe constitúe o fin último da obra. Aproveitando a estadía de Franco en Meirás para pasar o verán, o protagonista desvía o seu obxectivo

11 Neste sentido, concordamos con Hans Lauge Hansen en que "el diálogo con los discursos periodísticos e historiográficos ha dejado una impronta visible en el sentido de que una serie de novelas dedicadas a este tema hacen mímesis de ese mismo diálogo, intentando así exponer las condiciones ideológicas y sociales del proceso de construcción de la memoria cultural de una comunidad determinada" (Hansen 2012: 83). 
inicial e idea un plan para atentar contra o ditador. Porén, o relato remata coa morte de Artieda tras unha longa persecución policial, simbolizando a derrota colectiva, que se explicita nos derradeiros pensamentos do protagonista -"nunca o imos conseguir"- e no "pánico que lle produce saber que todo é inútil" (Rei Núñez 2000: 226).

A técnica multiperspectivista achega ao lector, en cada caso, a historia de como cada personaxe chegou á situación actual e, sobre todo, a información sobre cales foron as diferentes motivacións que o levaron a participar na resistencia cívica contra a ditadura. A través de monólogos interiores coñecemos as súas vivencias pasadas, nas que todo o relacionado coa guerra civil ocupa habitualmente un lugar preferente, as súas circunstancias individuais e a miúdo os seus conflitos internos entre o persoal e o político. Así, a pesar de a acción estar localizada en 1959, a memoria do 36 está moi presente ao longo da novela e condiciona a actuación de moitos dos personaxes, que converten ao lector en testemuña do seu pasado. Con todo, esa memoria, traumática en moitos casos, aparece relegada sempre ao ámbito privado e aos espazos reservados aos vencidos nesa sociedade fragmentada que representa Rei Núñez, de maneira que o recordo e homenaxe dos mártires da guerrilla, por exemplo, se produce sempre na clandestinidade e nunca ten carácter oficial.

No que á importancia do pasado inmediato se refire, destaca especialmente o personaxe de Mateo Lan, un vello cego que representa a memoria viva da Segunda República e do golpe de estado do 36, contando historias de presos e asasinados a mans dos fascistas no parladoiro clandestino en que se converte a tenda fotográfica de Querentes. Simúlase así unha transmisión oral e interxeracional da memoria republicana no ámbito privado - cando a porta da tenda está pechada é cando el pode xirar "a manivela da memoria" (Ibid.: 35) - que asegura a súa pervivencia pese á censura, silencio e manipulación do relato histórico impostos pola ditadura. Embora se refira tamén ao seu activismo republicano e sindical nos anos previos á guerra, Mateo representa sobre todo a memoria da represión falanxista na cidade, cuxos episodios, relata ante un auditorio atento porque, como sinala unha das personaxes, el "é a memoria da nosa vida" e "as súas historias son parte da nosa vida" (Ibid.: 35). Nel subxace unha intención de transmitir todo o que viu -torturados, fusilados, afogados- para que quede gardado antes de el morrer, de asegurarse de que as seguintes xeracións conserven esa memoria, a da atrocidade fascista durante e despois da guerra.

\subsection{Como levar un morto}

Como levar un morto, publicada en 2001 por Xesús Rábade Paredes, é unha novela fragmentaria, de perspectiva múltiple e conformada por varias voces narrativas que se entrecruzan dificultando a lectura en numerosas ocasións. O relato articúlase en once capítulos - de "Febreiro, 1999" a "Decembro, 1999"- a modo de diario do derradeiro ano de vida de Amador Souto, que decide escribir a súa historia para que non se esqueza. Souto é un home esquizofrénico que reflexiona sobre a memoria, a desgraza, a inxustiza e a dor que lle provoca cargar con varios crimes da posguerra que lle pesan como se levase perpetuamente enriba un morto, en especial o asasinato de seu pai Ovidio. Ademais de recuperar a historia de toda a súa vida e a dos seus pais, o relato refírese á actualidade do protagonista e á situación política actual, contra a que dirixe fortes e directas críticas. Aliás, a modo de collage, a novela incorpora cartas que intercambian Amador e a súa namorada Isaura, que se converte en interlocutora de boa parte do relato embora estea morta, documentos como o da instrución policial sobre a morte do pai no ano 45 e o informe psiquiátrico do protagonista ou fragmentos, traducidos para o galego, de La historia de España contada con sencillez de José María Pemán, por exemplo.

A novela estabelece unha relación de causalidade entre a violencia franquista e a enfermidade do protagonista, provocada polo trauma. $\mathrm{O}$ descendente do fusilado porta unha memoria traumática dos acontecementos vividos que semella ser a causante da esquizofrenia que padece, o que provoca unha interesante reflexión sobre o porvir das vítimas e as problemáticas herdanzas do franquismo, e en xeral do pasado violento, na actualidade. Xesús Rábade vai do concreto, a complexa vida de Amador, ao xeral para criticar a pervivencia do fascismo camuflado na democracia actual, a relación das elites franquistas cos políticos democráticos -sinalando nomes propios- e a xestión da Transición co consecuente pacto de esquecemento, cuxas consecuencias vive a sociedade de 1999. A obra non só permite, por tanto, observar o caótico e fragmentario proceso de rememoración do protagonista, isto é, da memoria individual, dificultado polo seu encerro no psiquiátrico, senón tamén, e en relación con esta, o modo de funcionamento da memoria colectiva, 
cuxas dinámicas de negociación se escenifican. A propia forma da novela, "circular e labiríntica", como é definida na contracapa do libro, reflicte que "tamén os camiños da memoria son moitos e confusos e hai risco de perder o paso ás veces" (Rábade Paredes 2001).

As citacións da obra de Pemán, que constitúen frecuentes digresións históricas sobre a guerra civil e a ditadura, e, en xeral, a revisión de mitos franquistas como o que se refire aos "bandoleiros", isto é, ao discurso oficial creado polo réxime arredor dos fuxidos e da guerrilla armada que ocupou os montes galegos durante os anos da posguerra, son contrastadas polas voces narradoras que achegan novas perspectivas críticas e antagónicas en moitas ocasións. Neste sentido, a novela constitúe unha especie de deconstrución do relato franquista e, ao tempo, de reivindicación, a través dunha ficticia historia particular, dun novo relato sobre o pasado que se ve obrigado a loitar coa memoria hexemónica para colocar o foco na importancia da resistencia antifranquista en Galiza, na crueldade da represión exercida contra os seus compoñentes ou na participación da Igrexa na mesma represión e na transmisión desa memoria oficial construída polo franquismo.

\subsection{O tempo en ningunha parte}

Na novela de Xosé Manuel Martínez Oca atopamos unha acción principal ambientada no ano 1985 en que o protagonista que chega a unha vila do interior de Ourense e investiga a historia de Tomás Pazos, un veciño que fora deputado durante a segunda República, exiliado en Bos Aires a partir do 1936 e que regresara a Galiza a comezos da década dos cincuenta. Toda a novela xira en relación á tentativa de recuperación da memoria deste personaxe por parte do narrador-protagonista, que o que atopa é unha sociedade atrasada e amnésica que en moitos aspectos continúa ancorada no franquismo. O silencio arredor da figura de Pazos dificulta enormemente a investigación iniciada e a falta de fontes documentais fai que a memoria oral dalgún veciño disposto a falar sexa a única maneira de acceder ao pasado. Deste modo, a desmemoria constitúe un dos temas máis recorrentes ao longo da novela e, sobre todo, nos pensamentos do narrador: "en pouco máis de corenta anos non podía terse borrado de tal xeito a memoria de quen sen dúbida tivera que ser un dos políticos e empresarios máis importantes da bisbarra" (Martínez Oca 2003: 40).

Como tratamos de analizar por extenso nun traballo previo (Rivadulla Costa 2019), a través da mímese de memoria, a novela reflexiona criticamente sobre a xestión da memoria do 36 feita polo franquismo, a desmemoria imperante sobre o pasado republicano e a pervivencia desa memoria hexemónica e do pacto de silencio unha vez concluído -con suposto éxito- o proceso da Transición á democracia, algo incomprensíbel para un representante da $2^{\mathrm{a}}$ xeración como é o protagonista:

Rematara a dictadura, viña acabando por dar a entender, e agora todo o mundo era demócrata de toda a vida, así que do pasado daquela xente mellor non falar, o recordo podía ferir moitas susceptibilidades e as feridas volveríanse abrir sen proveito para ninguén. Mellor calar, esquecer e deixalas cicatrizar, porque non hai nada máis verdadeiro que eso de que o pasado, pasado está, e por máis voltas que queiramos darlle non hai ninguén que o poida modificar. (Martínez Oca 2003: 82)

\subsection{O exiliado e a primavera}

N'O exiliado e a primavera, gañadora do Premio Xerais no 2004, Manuel Veiga presenta a historia dun galeguista exiliado, Alexandre Marrube, que volta a Galiza corenta anos despois da súa marcha para acudir ao enterro da súa nai. A acción, situada no ano 75 , antes da morte do ditador, xira arredor do conflito de memorias que se produce entre o protagonista e os familiares e amigos cos que conversa no seu regreso, entre os que destacan a irmá e o cuñado, o Maxistrado, firmes defensores de que o país con Franco mellorou moito e todo marcha como debe, ou un mozo militante antifranquista, co que confronta posturas políticas, especialmente sobre o diferente concepto que ambos teñen da resistencia nos estertores do réxime. A desmemoria colectiva e a aparente satisfacción da sociedade coa ditadura fascista contra a que el loitou son inexplicábeis para o exiliado, que non recoñece o país que atopa, véndose abocado a repensar a memoria construída no exilio mexicano:

Ás veces tiña a sensación, quizais absurda, de que el sabía máis do país que todos os que viviran sempre nel. Fartárase de ouvir, durante anos, as novas de cada un dos que chegaban a México procedentes do interior, as súas anécdotas e experiencias, as atrocidades da represión, case sempre esaxeradas [...] que ben logo eran esmiuzadas centos de veces nas tertulias interminábeis dos exiliados. [...] Sabía máis, pero era todo pasado, un pasado sobre o que non había sequera con quen conversar, porque o que se encontrara era outro país. (Veiga 2004: 30) 
Ao estilo de Max Aub no seu simbólico diario La gallina ciega, no que o Veiga recoñece terse inspirado, a novela representa a amnesia da sociedade galega de 1975 sobre a época da República, que semella unha simple ilusión que nunca existira, pois "o que non se verbaliza non existe" (Veiga 2004: 112). Aliás, o autor reflexiona de maneira crítica, a través de Marrube, sobre o carácter construído, selectivo e inestábel da memoria, ao tempo que procura a reflexión do lector contemporáneo. Coa intención de contrastar a memoria sobre os episodios de violencia do 36 que conserva o exiliado coa construída en Galiza polos vencedores, isto é, de explicitar a importancia de quen se encargue de construír o discurso creado sobre o pasado, o autor alude a personaxes históricos como Luís Moure Mariño, cuxo relato sobre a entrega submisa de Galiza ao franquismo cuestiona. En suma, a incomprensión do protagonista d'O exiliado e a primavera, coa que é doado que o lector ou lectora empatice en moitos momentos, simboliza por extensión ou metonimia a desesperanza ante o esquecemento predominante na sociedade galega sobre o pasado traumático colectivo, constatando desde o ano 2004 unha realidade que xa se perfilaba na altura da década dos setenta: a complexa tarefa de recuperación da memoria histórica. Como conclúe o protagonista, "Dentro de vinte ou trinta anos non serán precisos historiadores, senón arqueólogos. Até a romanización semellará máis doada de comprender" (Ibid.: 135).

\subsection{Home sen nome}

Na novela Home sen nome (2006), unha das máis destacadas achegas de Suso de Toro ao corpus da ficción memorialística galega, o autor presenta unha acción principal que se desenvolve nun hospital actual de Santiago de Compostela, onde Nano -un mozo que fai as veces de interlocutor- e un vello fascista de case cen anos que agoniza comparten cuarto. Neste caso son os delirios, reflexións e diálogos do ancián os que constitúen a vía do acceso ao pasado dentro da novela. A memoria oral do verdugo permite ao lector coñecer a súa espantosa biografía: formado no Berlín próximo á ascensión de Hitler, ao que apoia con convicción, volvera a España para se unir aos grupos fascistas que preparaban o golpe de estado e poder levar a cabo a "limpeza" do país; tras loitar na guerra civil e decepcionado coa nova España de Franco, incorpórase á División Azul para seguir loitando. Con todo, o personaxe declara en ocasións que tanto lembrar faino sufrir, máis que o seu propio estado físico:
Memoria. Teño. Non había de ter, mais teño. Teño toda a memoria comigo, e houbo anos e anos e non lembraba e agora, mira ti, agora abriuse algunha porta e sae toda a memoria para fóra, estame a vir. Toda. E non dá marchado a condenada. Teño medo a que sexa moita, a que sexa de máis. É un castigo non esquecer. (De Toro 2006: 73)

As conversas que mantén o personaxe co compañeiro de cuarto, coas enfermeiras ou cunha escritora que acode ao hospital moi interesada no seu testemuño porque anda a preparar un documental sobre a traumática historia das Marías compostelás son o medio perfecto para que esa memoria oral se despregue no plano actual. A historia do vello verase reflectida no documental, un produto cultural do novo milenio, como na novela de De Toro, de modo que a metaficción explicita aquí o paso da memoria oral e viva á memoria cultural que representarían ambas producións: o fictivo documental e a novela real. Embora non poidamos afrontar aquí unha análise en profundidade da novela como nos gustaría, cómpre indicar que un dos temas centrais que aborda Home sen nome é, do noso punto de vista, a xestión do pasado traumático na actualidade, colocando o foco especialmente no modo en que os vitimarios e os seus descendentes afrontan as consecuencias da violencia exercida décadas atrás. Un exemplo significativo atópase no capítulo 8 , nunha conversa que se produce entre Nano e os enfermeiros do hospital, onde comentan que o ancián protagonista non ten boa fama porque foi malo nos tempos da guerra, "contos de vellos" que provocaran que un enfermeiro se negase a atendelo porque matara a seu avó. Os efectos da desmemoria colectiva fanse explícitos cando ambos personaxes coinciden en sinalar, porén, que "esas historias, xa se sabe, non se sabe ben o que pasou" nin se sabe nunca, por suposto, "quen foi" (Ibid.: 96).

\subsection{Non hai noite tan longa}

Máis un exemplo representativo da tendencia da mímese de memoria na narrativa galega actual é Non hai noite tan longa (2011) de Agustín Fernández Paz. Non nos deteremos nela por estar estudada xa en profundidade desde este punto de vista noutros traballos (Rivadulla Costa 2018), mais require unha breve mención por constituír un exemplo paradigmático da nova narrativa memorialística galega e, sobre todo, para o que aquí nos interesa, cómpre destacala pola realista representación que realiza o autor do conflito de memorias existente na sociedade 
galega contemporánea -a acción localízase no ano 2002- entre os partidarios de coñecer o pasado, isto é, de recuperar a memoria histórica, e os defensores de deixar as cousas como están, non removendo a historia nin reabrindo "vellas feridas", que, como na novela de Martínez Oca tratada unhas liñas atrás, dificultan a investigación do protagonista sobre a condena do pai por parte da xustiza tardofranquista, ben como a reparación da súa figura. O final feliz da novela mostra, no entanto, que si é posíbel a reparación a través de accións individuais que contribúan á construción dunha memoria cultural que reivindique o pasado republicano fronte á memoria oficial franquista. Memoria, xustiza e reparación, o lema do movemento memorialista galego, ben podería servir para definir o tema central da obra.

\subsection{Seique}

Finalmente, cómpre engadir a esta nómina de títulos, xa a modo de epílogo, a obra coa que Susana Sánchez Aríns revolucionou a literatura galega da memoria. Seique, publicada no ano 2015 e recentemente traducida ao español, rompe coas principais tendencias da narrativa memorialística e, ao tempo, cos moldes xenéricos, ao se presentar non como unha novela, nin como un poemario, nin como un ensaio, embora teña trazos de todos eles, senón como unha "estória de vida insignificante, anónima, para abordar uma reflexão sobre a [des]memória e as maneiras de construir a História" (Sánchez Arins 2015). A través de fragmentos, breves píldoras ou retallos que se moven entre a memoria, a crónica histórica e, ás veces, a poesía, a voz narrativa, trasunto da da propia autora, investiga a figura do seu tío Manuel, un falanxista que fora responsábel de varias mortes, aínda que para iso teña que reconstruír toda a historia familiar. A incorporación de diálogos, poemas, contos, coplas ou refráns fala, como o propio título, da dificultade de reconstruír un pasado silenciado do que ninguén parece saber nada con certeza. Porén, o fundamental da obra, como anuncia o paratexto citado anteriormente, é a reflexión sobre a memoria, o esquecemento, a necesidade de abrir as fosas, de coñecer a violencia represiva do 36 e, sobre todo, de sinalar os vitimarios responsábeis da "política do terror". Coidamos que é unha das propostas máis interesantes dos últimos anos no que ao tema se refire e que merece, sen dúbida, unha abordaxe urxente en profundidade, así como unha maior difusión para o seu coñecemento, na procura da reflexión colectiva que a obra propón.

\section{Remate}

Aínda que o tema permitiría e requiriría dunha análise con maior profundidade de cada unha das obras para a que non dispoñemos de espazo, coidamos que esta breve revisión deu para ver que títulos tan diversos como Expediente Artieda, $O$ exiliado e a primavera, Home sen nome, ou Seique representan unha narrativa que pretende ir máis alá da función de recuperación de historias e memorias silenciadas que lle tiña sido tradicionalmente atribuída a esta literatura da memoria para, a través da "mímese de memoria", reflexionaren sobre a recuperación da memoria histórica por parte das novas xeracións, sobre os procesos de transmisión interxeracional desas memorias silenciadas durante décadas, sobre a dificultade de acceder á memoria dun tempo cada vez máis afastado do que as testemuñas directas están a desaparecer, sobre a desmemoria e amnesia colectivas ou sobre o silencio e negacionismo aínda instaurados en parte da sociedade galega contemporánea.

\section{Referencias bibliográficas}

Aguilar Fernández, Paloma e Leigh A. Payne (2018): El resurgir del pasado en España. Barcelona: Taurus.

De Toro, Suso (2006): Home sen nome. Vigo: Xerais.

Domínguez, Andrés e Antonio Somoza (2013): "Víctimas y memoria del 36: De la resistencia callada al voto en la transición", Memória antifranquista del Baix Llobregat 9/13, pp. 74-77.

Erll, Astrid (2008): “Cultural Memory Studies. An Introduction”, en A. Erll e A. Nünning (eds.), Cultural Memory Studies. An International and Interdisciplinary Handbook. New York: Walter de Gruyter, pp. 1-18. (2011): Memory in Culture. Hampshire: Palgrave Macmillan.

Erll, Astrid e Ann Rigney (2006): "Literature and the production of cultural memory: Introduction", European Journal of English Studies 10/2, pp. 111-115.

Erll, Astrid e Ansgar Nünning (eds.) (2008): Cultural Memory Studies. An International and Interdisciplinary Handbook. New York: Walter de Gruyter.

(2016): “Conceitos e métodos para o estudo da literatura e/enquanto memória cultural”, en F. Mota Alves, L. Afonso Soares e C. Vasconcelos Rodrigues (eds.), Estudos da memória. Teoria e análise cultural. Ribeirão: Edições Húmus, pp. 245-66. 
Fernández Paz, Agustín (2011): Non hai noite tan longa. Vigo: Xerais.

Fernández Prieto, Lourenzo (2007): Século XX. Unha Economía: Dúas Sociedades. Volume 2: Atraso económico nunha sociedade destruída. A Coruña: La Voz de Galicia.

(2009): “Actitudes sociales y políticas en la denominada recuperación de la memoria histórica. Galicia. El proyecto de investigación interuniversitario «Nomes e voces»", Pasado y Memoria. Revista de Historia Contemporánea 8, pp. 131-157.

(2011): “Conservación y olvido de los pasados incómodos en las sociedades contemporáneas", en E. Rey Tristán e P. Cagiao Vila (coords.), Conflicto, memoria y pasados traumáticos: El Salvador contemporáneo. Santiago de Compostela: Universidade de Santiago de Compostela, pp. 95-120.

Fernández Prieto, Lourenzo e Aurora Artiaga (2013): "Políticas de la memoria. Galicia", Memória antifranquista del Baix Llobregat 9/13, pp. 78-83.

Gómez López-Quiñones, Antonio (2006): La guerra persistente. Memoria, violencia y utopía: representaciones contemporáneas de la Guerra Civil española. Frankfurt-Madrid: Iberoamericana Vervuert.

Hansen, Hans Lauge (2012): "Formas de la novela histórica actual", en H. L. Hansen e J. C. Cruz Suárez (eds.), La memoria novelada. Hibridación de géneros y metaficción en la novela española sobre la guerra civil y el franquismo (2000-2010). Berna: Peter Lang, pp. 83-103.

Hansen, Hans Lauge e Juan Carlos Cruz Suárez (eds.) (2012): La memoria novelada. Hibridación de géneros y metaficción en la novela española sobre la guerra civil y el franquismo (2000-2010). Berna: Peter Lang.

Liikanen, Elina (2015): El papel de la literatura en la construcción de la memoria cultural: Tres modos de representar la Guerra Civil española y el franquismo en la novela española actual. Tese de doutoramento inédita. Santiago de Compostela: Universidade de Santiago de Compostela.

Martínez Oca, Xosé Manuel (2003): O tempo en ningunha parte. A Coruña: Espiral Maior.

Míguez Macho, Antonio (2009): Xenocidio e represión franquista en Galicia. Santiago de Compostela: Lóstrego.

Mota Alves, Fernanda; Luísa Afonso Soares e Cristiana Vasconcelos Rodrigues (eds.) (2016): Estudos da memória. Teoria e análise cultural. Vilanova de Famalição: Húmus.

Neumann, Birgit (2008): “The Literary Representation of Memory”, en A. Erll e A. Nünning (eds.), Cultural Memory Studies. An International and Interdisciplinary Handbook. New York: Walter de Gruyter, pp. 333-344.

Pereira, Dionísio; Eliseo Fernández e Emilio Grandío (2011): "Limiar", en A represión franquista na comarca da Coruña. Vidas na memoria. Ames: Laiovento, pp. 7-32.

Rábade Paredez, Xesús (2001): Como levar un morto. Santiago de Compostela: Sotelo Blanco.

Rei Núñez, Luís (2000): Expediente Artieda. Vigo: Xerais.

Rivadulla Costa, Diego (2018) "Non hai noite tan longa: investigación, historia e memoria do tardofranquismo", Madrygal. Revista de Estudios Gallegos 21, pp. 205-216, DOI: https://doi.org/10.5209/ MADR.62601.

(2019): "Representación literaria da memoria e consecuencias da Transición na sociedade galega posfranquista: aproximación á novela $O$ tempo en ningunha parte de Xosé Manuel Martínez Oca", Romanica Olomucensia 31/2, pp. 269-283, DOI: 10.5507/ro.2019.019.

Ruiz, Pedro (2007): "Los discursos de la memoria histórica en España”, Hispania Nova 7, http://hispanianova.rediris.es/7/dossier/07d001.pdf.

Sánchez Arins, Susana (2015): Seique. Santiago de Compostela: Através.

Santamaría Colmenero, Sara (2013): La palabra como acontecimiento: Segunda República, Guerra Civil y posguerra en la novela actual (1990-2010). Tese de doutoramento inédita. Valencia: Universitat de València.

(2018): "Memoria cultural”, en R. Vinyes (ed.), Diccionario de la memoria colectiva. Barcelona: Gedisa, pp. 283-284.

Thompson, John (2009): As novelas da memoria. Vigo: Galaxia.

Veiga, Manuel (2004): O exiliado e a primavera. Vigo: Xerais.

Velasco Souto, Carlos (2006): 1936. Represión e alzamento militar en Galiza. Vigo: A Nosa Terra.

(2011): "Repressom franquista e memória histórica na Galiza. Historiografía e linhas de pesquisa fundamentais", Murguía. Revista galega de historia 23-24, pp. 73-96.

- (2012): "A memória coletiva como elemento sustentador da identidade. Repressom franquista e restauraçom da memória democrática na Galiza”, en P. Godinho (ed.), Usos da memória e práticas do património. Lisboa: Edições Colibri / Instituto de Estudos de Literatura Tradicional, pp. 61-81.

Vilavedra, Dolores (2011): "Guerra civil y literatura gallega", Cuadernos de la Revista internacional de estudios vascos 8 , pp. 62-77. 